\title{
Numerical Study of Characteristics of Underexpanded Supersonic Jet
}

\author{
Priyadharshini Murugesan², Arjun Biju Kumar¹, Akhil Teja Kambhampati , Shashank Pillai ${ }^{1}$, Girish \\ Chandar Chandrasekar ${ }^{1}$, Srikrishnan Ambattu Raghavannambiar², Ratna Kishore Velamati1 ${ }^{1, *}$
}

\author{
Murugesan P (D) https: / /orcid.org/0000-0003-4404-3718 \\ Arjun B (D) https://orcid.org/0000-0003-1344-4180 \\ Srikrishnan AR (D) https: / /orcid.org/0000-0002-5728-2374 \\ Ratna KV (D) https://orcid.org/0000-0002-9490-5454
}

How to cite

Murugesan P; Arjun B; Akhil TK; Shashank P; Girish CC; Srikrishnan AR; Ratna KV (2020) Numerical Study of Characteristics of Underexpanded Supersonic Jet. J Aerosp Technol Manag, V12: e4220. https://doi.org/10.5028/ jatm.v12.1126

\begin{abstract}
Correlations for the supersonic jet characteristics, the mean shock cell length and the supersonic core length, have been obtained in terms of the jet parameters. The jet parameters considered in this study are the exit diameter of the nozzle ( $d_{\mathrm{f}}$ ), the design Mach number $\left(\mathrm{M}_{\mathrm{e}}\right)$, the nozzle pressure ratio (NPR) and the ratio of specific heats of the medium $(\gamma)$. The parameters were varied as follows: exit diameters, from 0.5 to 25 mm; Mach number from 1 to 3; the NPR from 2.14 to 35 . Initially, working fluid used is cold air and then effect of variation of $\gamma$ is taken into consideration. The computational model has been validated and then used for all the numerical simulations. A quadratic fit for both characteristics has been obtained which is applicable to any supersonic jet. The correlations developed are valid within the respective ranges of the parameters stated above.
\end{abstract}

KEYWORDS: Supersonic jet; Shock cell length; Supersonic core length; Numerical analysis.

\section{INTRODUCTION}

Supersonic jets have diverse applications in modern world. They are being used in numerous technology domains and devices that include the aviation industry, medicine, inkjet printers and high-speed combustion systems. Supersonic jets are characterized by the presence of shocks. Shocks are formed in the flow field when the nozzle pressure ratio (NPR) is off-design. For a given nozzle geometry, the design exit Mach number occurs over a range of values of NPR. When the actual NPR is less than the design value, the jet is said to be over expanded and, when it is greater than the design NPR, it is said to be underexpanded. An uncontrolled supersonic jet is characterized by two parameters, namely the supersonic core length and the shock cell length. Several numerical and experimental studies have been reported on supersonic jets for various parameters such as nozzle configuration (Foss et al. 1989; Saddington et al. 2002; Otobe et al. 2008; Cai et al. 2010; Cuppoletti et al. 2014), acoustics (Tam and Tanna 1982; Alkislar et al. 2004; Singh and Chatterjee 2007), shock reflection (Vuillon et al. 1996; Ivanov et al. 1998; Hadjadj et al. 2004), shock hysteresis (Yasunobu et al. 2006; Matsuo et al. 2011), Mach reflection (Chow and Chang 1972; 1975; Li and Ben-Dor 1998; Schmisseur and Gaitonde 2011) and flow separation taking place at the nozzle exit (Xiao et al. 2007, Shimshi et al. 2010). 
$\mathrm{Hu}$ and McLaughlin (1981) studied the nature of the flow and acoustic properties of the low Reynolds number (of the order of 8,000) underexpanded supersonic jets with Mach numbers 1.4 and 2.1. They observed that the noise released by the jets was very similar in characteristics to the jet shock screech phenomenon observed in high Reynolds number supersonic jets.

Otobe et al. (2008) have worked on the effect of three nozzle geometries on the near field structure of a highly underexpanded sonic jet. The study involves variation of nozzle parameters such as nozzle angle and the exit diameter. Their results show that the concept of an effective diameter removes the influence of the nozzle exit diameter on the position of the Mach disk. (Mach disk is a shock wave standing perpendicular to the direction of exhaust flow - Mach disk is formed as the reflected oblique shock waves from the nozzle walls approach the center of the jet axis). The near field flow structure is, thereby independent of the nozzle configuration but is a strong function of the pressure ratio.

Laser Doppler velocimetry of underexpanded supersonic free jets was performed by André et al. (2013). Two Mach numbers of 1.15 and 1.35 were studied. André et al. (2014) have used particle image velocimetry method to study the underexpanded supersonic jets mixing layer. The experiments were performed for the NPR range of 2.14-3.67 with a convergent nozzle of exit diameter $38.7 \mathrm{~mm}$. They found that the behavior of slightly underexpanded jets is similar to that of jets at high subsonic Mach numbers. For higher NPR, first shock cell seems to show higher velocity fluctuations.

Tam and Tanna (1982) have performed a theoretical and experimental analysis of the noise associated with the shock for underand overexpanded supersonic jets. Their results show similarities in the shock-related screech for the mildly underexpanded jet and the subsonic jets. Their multiple scale model of supersonic jets shows a dependency relation of the shock cell structure and the noise intensity. Punekar et al. (2017) experimentally investigated the nonlinear effects between crackle and screech in the nearfield and far-field of an underexpanded supersonic jet at a design Mach number of $M=2$. They observed that crackle had faster decay than screech and that higher levels of crackle and screech at the near-field caused fatigue to the components of the aircraft. Kumar and Rathakrishnan (2013) has worked on the exit structure of a shock cell for a supersonic nozzle, for which a nozzle of diameter $13.02 \mathrm{~mm}$ was used. Mach number at the exit was kept to be 2 throughout all the cases where NPR was varied between 4 and 8. Their study was focused on the effectiveness of the controlled jet in increasing the mixing efficiency.

Studies on microjets, having diameters from 0.6 to $1.2 \mathrm{~mm}$, were performed by Scroggs and Settles (1996). The exit Mach numbers were varied from 1 to 2.8. They observed that Mach number dependence on supersonic core length for microjets related well with large scale supersonic jets. Phalnikar et al. (2007) have performed experiments on free and impinging supersonic microjets, having diameters of 100-1000 $\mu \mathrm{m}$, and an exit velocity of 300-500 m/s. Their pressure measurements using a pitot probe along the centerline show that the shock cell length and supersonic core length for the microjets were similar to the largescale supersonic jets having large Reynolds numbers.

Shirie and Seubold (1967) had developed a correlation for supersonic core length based on experimental data available up till that point of time. They considered supersonic jets having exit diameters from 0.25 to 17.7 inches, Mach numbers from 1 to 3.5 and jet exit pressures from 7.6 to 147 psia. They obtained the supersonic core length as a function of the ratio of exit pressure to the ambient pressure, the Mach number and the exit diameter of the nozzle. The generic correlation relating core length with jet parameters obtained was not explicitly specified.

To the best of the authors' knowledge, there does not seem to be a correlation for the supersonic core length and the mean shock cell length in terms of the jet parameters. The present work is to determine a generic correlation for uncontrolled supersonic jet characteristics in terms of jet parameters. The supersonic jet characteristics, supersonic core length and mean shock cell length are considered to be dependent on the exit jet Mach number (M), NPR and the nozzle exit diameter $\left(\mathrm{d}_{\mathrm{e}}\right)$. The exit jet Mach number was varied from 1 to 3, NPR from 2.14 to 35 and the exit diameter from 0.5 to $25 \mathrm{~mm}$. The supersonic jet core length and the mean shock cell length were calculated using two-dimensional axisymmetric computational fluid dynamics (CFD) simulations. Numerical simulations are performed using commercial CFD code FLUENT.

\section{COMPUTATIONAL MODEL}

Two-dimensional axisymmetric compressible Navier-Stokes equations were solved. Turbulence was modeled using renormalization group (RNG) k- $\varepsilon$ model. Air density was modeled using the ideal gas relation. Figure 1 shows the two-dimensional axisymmetric 


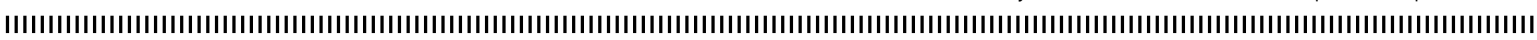

domain and the grid used for the present study. The computational domain along the axis is considered to be $35 \mathrm{~d}_{\mathrm{e}}$ and $12 \mathrm{~d}_{\mathrm{e}}$ in the radial distance from the axis. The total number of grid points varies from 44658 to 261823 as the nozzle exit diameter varies. The smallest grid spacing in the radial direction is 0.03 and $0.06 \mathrm{~d}_{\mathrm{e}}$ in the axial direction. The domain was meshed finer in the region close to the nozzle exit (up to 15 times $d_{e}$ in the axial direction) in comparison to the far field. The nozzle lip thickness is taken to be $4 \mathrm{~mm}$ for all the cases except $\mathrm{d}_{\mathrm{e}}=0.5 \mathrm{~mm}$. The second order upwind scheme is used to discretize the convective terms of the equations. A density-based solver has been used to solve the discretized equations.

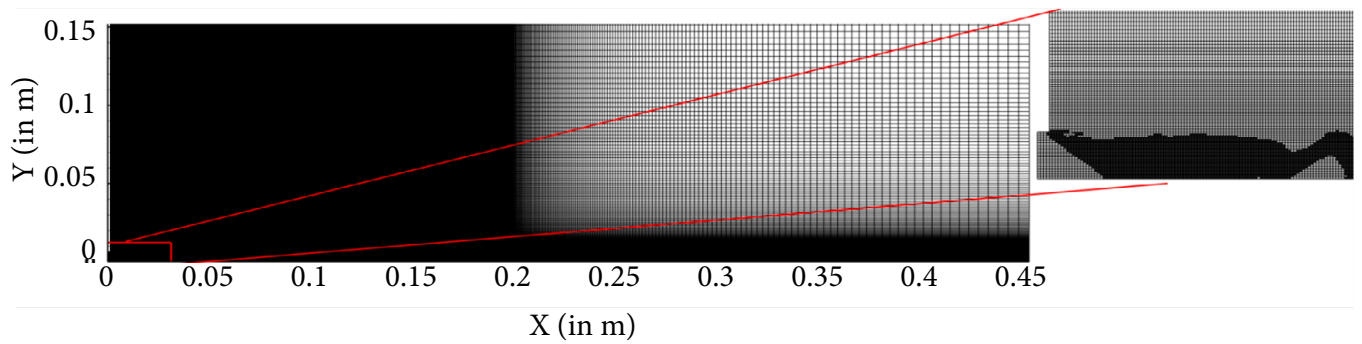

Figure 1. Typical computational domain and grid for $d_{e}=13.02 \mathrm{~mm}$

\section{BOUNDARY CONDITIONS}

The nozzle wall and the lip are modeled with no slip boundary wall conditions. At the nozzle exit, the total pressure, static pressure and the total temperature are specified. The total and static pressures vary with the nozzle pressure ratio $\left(\mathrm{NPR}=\mathrm{P}_{o s} / \mathrm{P}_{\mathrm{a}}\right)$. The surfaces around the domain are modeled as pressure inlets through which the ambient fluid enters at atmospheric pressure $\left(\mathrm{P}_{\mathrm{a}}\right)$; air leaves through the far-end surface which is taken as a pressure outlet.

\section{GRID INDEPENDENCE STUDY}

A comparison study to ensure the adequacy of grid resolution was carried out for the nozzle with exit diameter $\mathrm{d}_{\mathrm{e}}=13.02 \mathrm{~mm}$, Mach number, $M=2$ and NPR = 5. The grid was adapted based on gradient of static pressure to further resolve shock cell pattern. Table 1 shows summary of the grid independence study made for different grids. The supersonic core length $\left(\mathrm{L}_{\mathrm{c}}\right)$ is defined as the distance from the nozzle exit to the axial location along the axis, where the local flow Mach number drops below 1.0. It is observed that the mean shock cell length $\left(\mathrm{L}_{\mathrm{s}}\right)$ varies only by $0.17 \%$ after the first and the second levels of adaptation. In the case of core length $\left(\mathrm{L}_{c}\right)$, a variation of $1.11 \%$ is observed. Hence, first level adaption is used for further computations in the present work.

Table 1. Grid independence study performed for $d_{e}=13.02 \mathrm{~mm}, M=2, N P R=5$

\begin{tabular}{|c|c|c|c|}
\hline S No. & Number of nodes & $L_{c}(\mathrm{~mm})$ & $\mathbf{M e a n}_{\mathrm{s}}(\mathrm{mm})$ \\
\hline 1 & 114651 & 0.1765 & 0.018 \\
\hline 2 & 133753 & 0.1762 & 0.0178 \\
\hline 3 & 154163 & 0.1762 & 0.0178 \\
\hline
\end{tabular}

\section{VALIDATION OF NUMERICAL MODEL}

Figure 2a shows the variation of the normalized mean shock cell length $\left(\mathrm{L}_{\mathrm{s}}\right)$ with the NPR for present numerical model, the approximate formulation of Emden-Prandtl (Powell 2010) and the experimental results of Kumar and Rathakrishnan (2003). The exit diameter was $13.02 \mathrm{~mm}$ and exit Mach number was 2 (same as that of experimental conditions). The experiments are done by measuring the pitot pressure along intervals of $1 \mathrm{~mm}$. Hence, the uncertainty in the shock cell length is approximately $\pm 1 \mathrm{~mm}$. The numerical results are within the uncertainty limit. Also, the present numerical results reasonably agree with Emden-Prandtl 
formulation (Powell 2010). The increase in shock cell length with the increase in NPR predicted by the experimental data can also be seen from the numerical results. Figure $2 \mathrm{~b}$ compares the axial velocity along axis for the present numerical results with that of PIV data of André et al. (2013). The simulations were performed for exit diameter of $38.25 \mathrm{~mm}$ and NPR of 2.97, same as those of experimental data. It can be seen that the present model with RNG k- $\varepsilon$ is able to predict the axial velocity profile properly along the peak velocity magnitude. This shows that the present model can predict mean shock cell length and supersonic core length with reasonable accuracy.
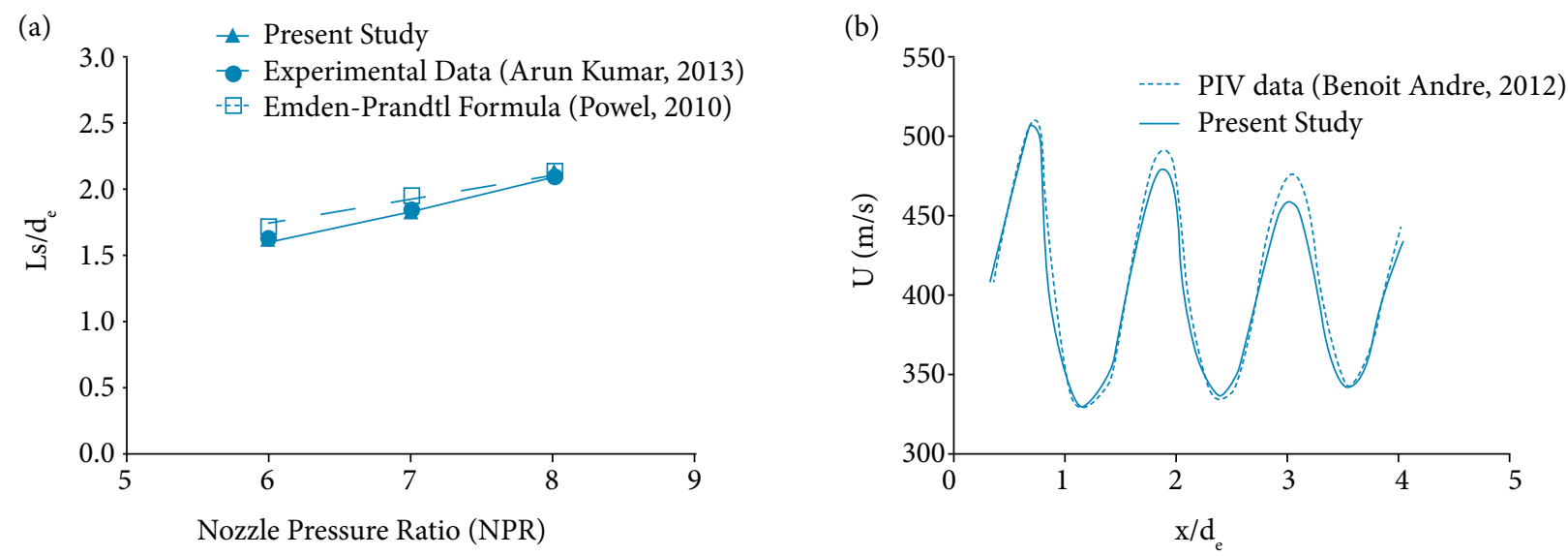

Figure 2. Validation of numerical model with experimental data of (a) normalized mean shock cell length with exit diameter (b) PIV data along the axis line.

\section{RESULTS AND DISCUSSION}

Numerical simulations were performed to calculate mean shock cell length and supersonic core length. The exit jet Mach number was varied from 1 to 3, NPR from 2.14 to 35 and the exit diameter from 0.5 to $25 \mathrm{~mm}$. A survey of the literature in this field shows that the shock cell parameters - mean shock cell length $\left(\mathrm{L}_{s}\right)$ and supersonic core length $\left(\mathrm{L}_{\mathrm{c}}\right)-$ are dependent on exit diameter $\left(d_{e}\right)$, exit Mach number, $M_{e}$, Total pressure $\left(P_{o}\right)$, ambient pressure $\left(P_{a}\right)$ and ratio of specific heats $(\gamma)$. This functional relationship can be represented in Eq. 1:

$$
\mathrm{L}_{\mathrm{s}}=\mathrm{f}\left(\mathrm{d}_{\mathrm{e}}, \mathrm{M}_{\mathrm{e}}, \mathrm{P}_{\mathrm{o}}, \mathrm{P}_{\mathrm{a}}, \gamma\right)
$$

In the present study, $\gamma$ is restricted to 1.4. Phalnikar et al. (2007) have obtained relationship for $\mathrm{L}_{\mathrm{s}} / \mathrm{d}_{\mathrm{e}}$ for microjets as a function $M_{j}$. It should be noted that $M_{j}$ will be a function of NPR. Shirie and Seubold (1967) have developed correlation for $L_{c} / d_{e}$ as function $\mathrm{P}_{\mathrm{e}} / \mathrm{P}_{\mathrm{a}}, \mathrm{M}_{\mathrm{e}}$ and $\gamma$. Hence, $\mathrm{L}_{\mathrm{s}}$ can be considered to be functionally related as Eq. 2 :

$$
L_{s} / d_{e}=f\left(M_{e}, P_{o} / P_{a}\right)=f\left(M_{e}, N P R\right)
$$

Figure 3 shows variation of $\mathrm{L}_{\mathrm{s}} / \mathrm{d}_{\mathrm{e}}$ with NPR for various exit Mach numbers and exit diameters. It can be clearly seen in Fig. $3 \mathrm{~b}$ that for various exit diameters, $\mathrm{L}_{\mathrm{s}} / \mathrm{d}_{\mathrm{e}}$ remains almost the same. Ls/de increases with NPR and this change in $\mathrm{L}_{\mathrm{s}} / \mathrm{d}_{\mathrm{e}}$ is more for higher values of exit Mach number. $\mathrm{L}_{\mathrm{s}} / \mathrm{d}_{\mathrm{e}}$ was multiplied with factor similar as that given by Shirie and Seubold (1967). The expression for the $\mathrm{L}_{\mathrm{s}} / \mathrm{d}_{\mathrm{e}}$ obtained is given in Eq. 3. 
(a)

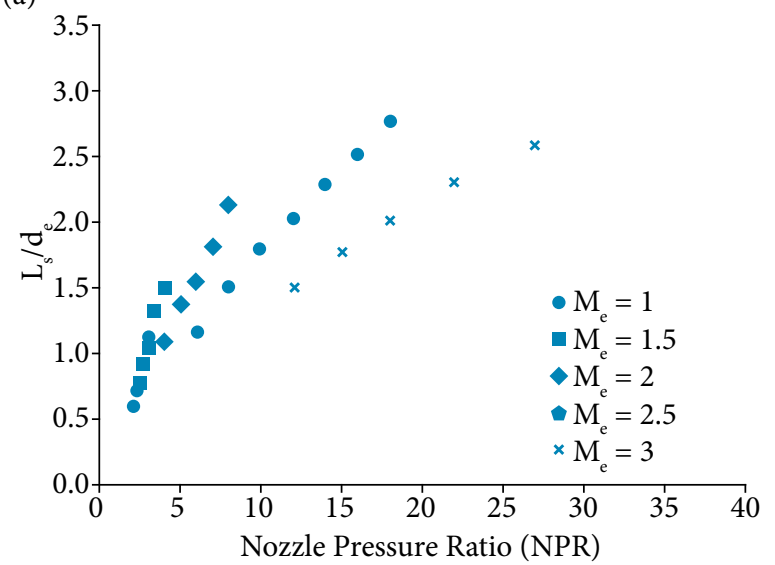

(b)

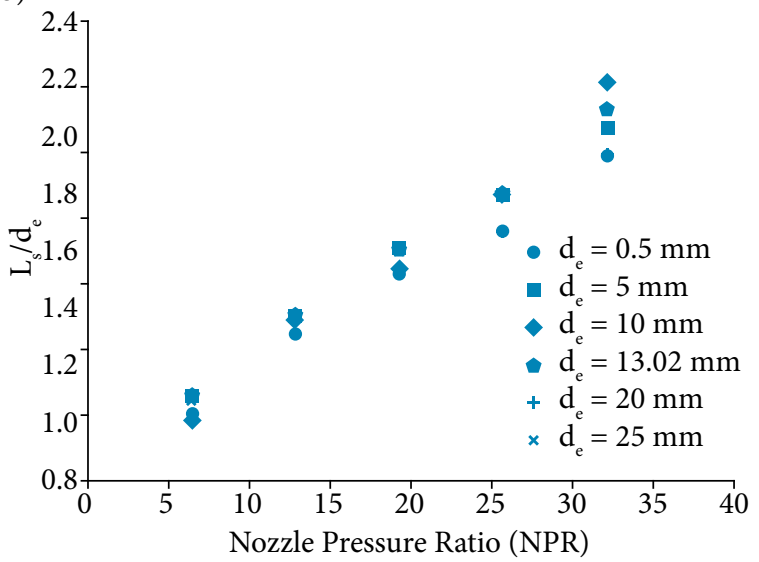

Figure 3. Ls/de variation with NPR for various values of (a) exit Mach number $\left(M_{e}\right)$ and (b) exit diameter $\left[d_{e}\right]$.

$$
\frac{\mathrm{L}_{\mathrm{s}}}{\mathrm{d}_{\mathrm{e}}}=\mathrm{e}^{-\left(\mathrm{C}^{*} \gamma^{*} \mathrm{M}_{\mathrm{e}}^{2}\right)}\left[-4.405 \mathrm{E}-3 *(\mathrm{NPR})^{2}+0.4181 * \mathrm{NPR}+0.1359\right]
$$

where $\mathrm{C}$ is a constant. This constant was found to be 0.09 leading to convergence of all the data points as given in Fig. $4 \mathrm{a}$. The curve fitting was used to establish a correlation for $\mathrm{L}_{\mathrm{s}} / \mathrm{d}_{\mathrm{e}}$. Different fits such as quadratic, cubic and exponential fits were used and it was found that quadratic fit gave minimum error out of the three (Fig. 4a). The root mean square errors for the quadratic, cubic and exponential fits were found to be $0.001032,0.0016$ and 0.00107 respectively. Figure $4 \mathrm{~b}$ shows a comparison of mean shock cell length obtained from correlation and simulation. The correlation has an error of $\pm 10 \%$ and $95 \%$ of the data points were within the band. The error is large in the case of sonic conditions as most of trend line equations are not able to fit well for NPR range of 2.14-4.00.

(a)

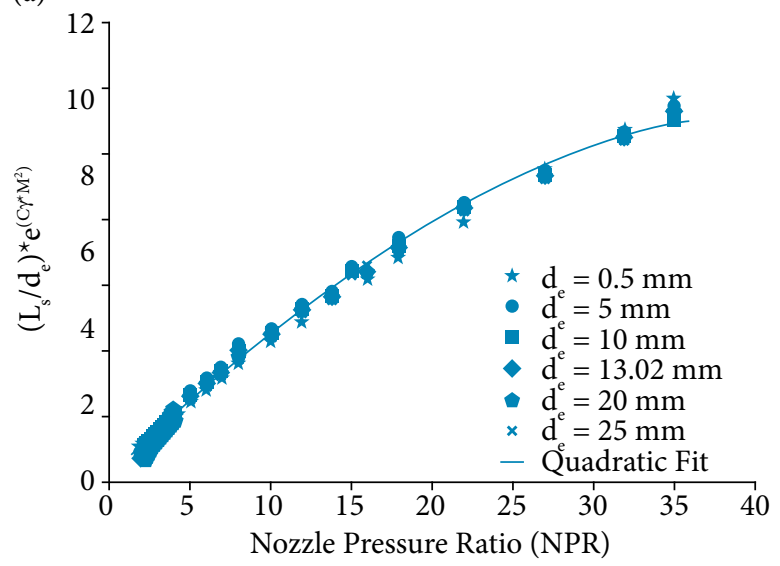

(b)

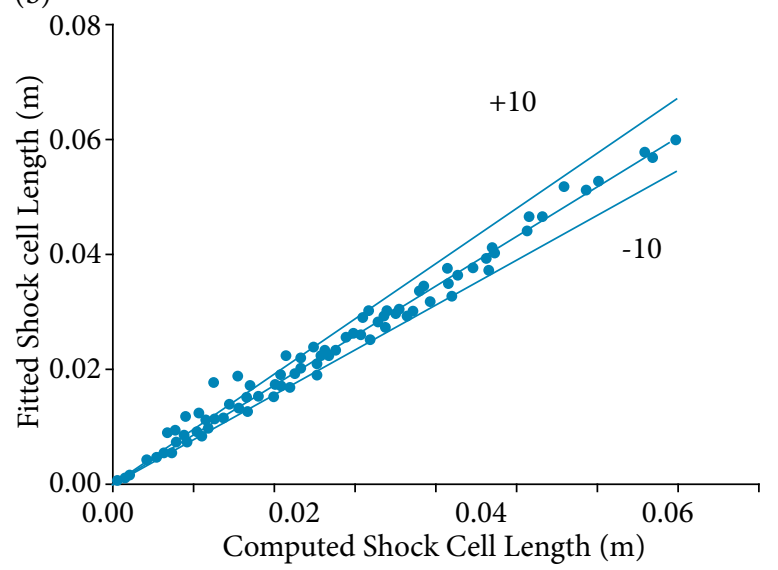

Figure 4. (a) Computed mean shock length data for correlation fit, (b) fitted vs computed shock cell length with error limits.

A similar procedure was followed for the supersonic core length $\left(\mathrm{L}_{\mathrm{c}}\right)$ to obtain a correlation. The parameter $\mathrm{C}$, in the exponential term was found to be a function of the exit diameter, $d_{e}$. The expression for $L_{c} / d_{e}$ was obtained as shown is Eq. 4 .

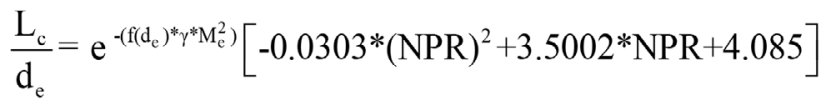


where $f\left(d_{e}\right)=12.40^{\star} d_{e}^{2}-0.6411^{\star} d_{e}+0.0914$

As in the case of $\mathrm{L}_{\mathrm{s}}$ it was observed that a quadratic fit predicted the curve with the least error. Figure $5 \mathrm{~b}$ shows a comparison of mean shock cell length obtained from correlation and simulation. The correlation has an error of $\pm 10 \%$ and $95 \%$ of the data points were within the band.
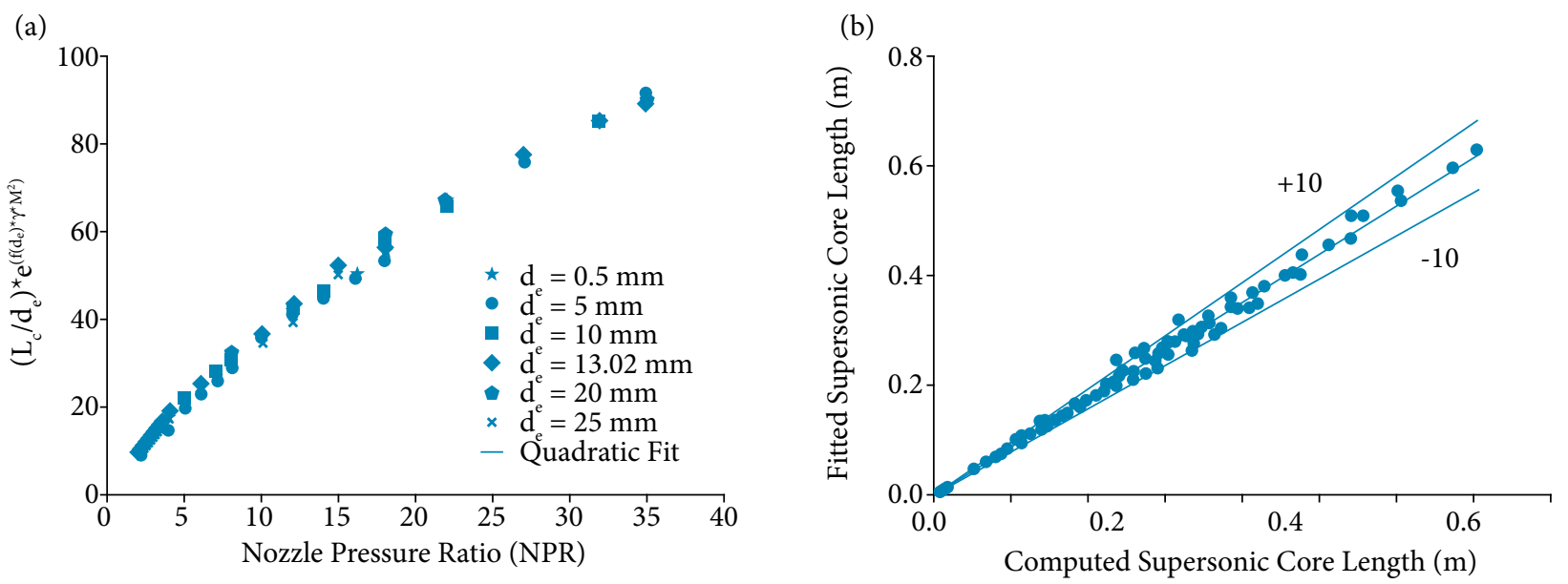

Figure 5. (a) Computed supersonic core length data for correlation fit, (b) fitted vs computed supersonic core length with error limits.

Finally, the study was extended to analyze the influence of the ratio of specific heats $(\gamma)$ on jet parameters. Apart from air, fluids such as $\mathrm{CO}_{2}(\gamma=1.289)$, Argon $(\gamma=1.667)$ and a hypothetical fluid with $\gamma=1.5$ were used. Simulations were run for the same inlet conditions as in the previous section for a nozzle exit diameter, $\mathrm{d}_{\mathrm{e}}=13.02 \mathrm{~mm}$.

Figure 6a shows the $\mathrm{L}_{\mathrm{s}} / \mathrm{d}_{\mathrm{e}}$ for various medium with $\gamma$ varying from 1.28 to 1.67 . In order to make the correlation generic same quadratic expression is used in the figure and the fit was good except in the NPR range of $2.14-5$. The expression for the $\mathrm{L}_{\mathrm{s}} / \mathrm{d}_{\mathrm{e}}$ was obtained in Eq. 5 .
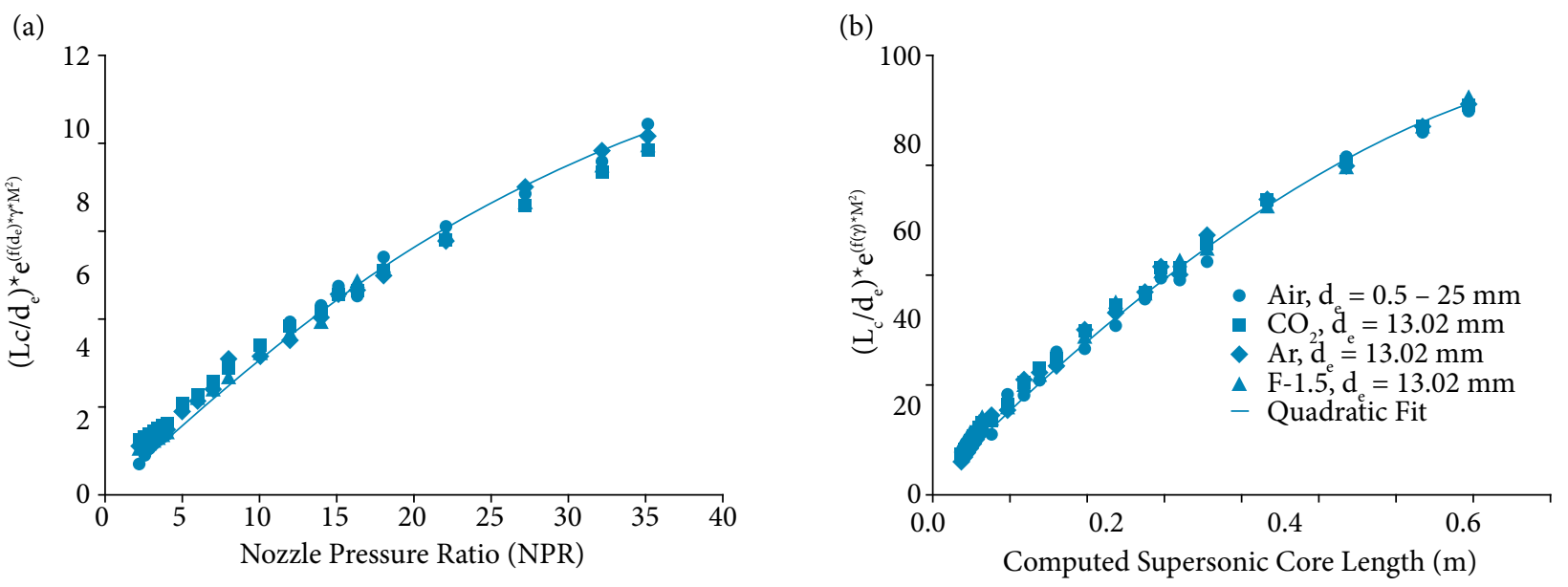

Figure 6. Computed mean shock cell length and supersonic core length data for correlation fit.

$$
\frac{\mathrm{L}_{\mathrm{s}}}{\mathrm{d}_{\mathrm{e}}}=\mathrm{e}^{-\left(\mathrm{f}(\mathrm{\gamma})^{*} \mathrm{M}_{\mathrm{e}}^{2}\right)}\left[-4.405 \mathrm{E}-3 *(\mathrm{NPR})^{2}+0.4181 * \mathrm{NPR}+0.1359\right]
$$




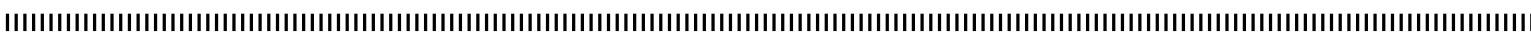

where, $f(\gamma)=0.1517^{\star} \gamma^{2}-0.5038^{\star} \gamma+0.5332$.

Figure $6 \mathrm{~b}$ shows the $\mathrm{L}_{\mathrm{c}} / \mathrm{d}_{\mathrm{e}}$ for various medium with $\gamma$ varying from 1.28 to 1.67 . Here also, the correlation expression has same quadratic expression which was obtained in the previous section. The expression for $\mathrm{L}_{c} / \mathrm{d}_{\mathrm{e}}$ was obtained in Eq. 6 .

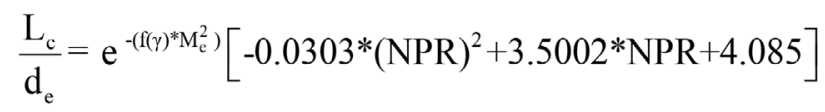

where, $f(\gamma)=-0.0276^{\star} \gamma^{2}+0.0448^{\star} \gamma+0.113$

For both the cases, the correlation has an error of $\pm 10 \%$ and $91 \%$ of the data points were within the band.

\section{CONCLUSION}

A two-dimensional axisymmetric CFD model using RNG k- $\varepsilon$ model was found to predict supersonic jet characteristics with reasonable accuracy. The supersonic jet parameters such as exit diameters (0.5 to $25 \mathrm{~mm}$ ), Mach number (1 to 3), NPR (2.14 to $35), \gamma(1.3-1.67)$ were taken into consideration in the parametric analysis. Correlations were developed for jet characteristics, mean shock cell length and supersonic core length. The correlations are valid over the above ranges of the respective parameters. The error for fitted correlation was less when fluid was considered to be air, compared to generic correlation for any fluid medium.

\section{ACKNOWLEDGMENTS}

The authors would like to acknowledge Dr. Arun Kumar, IIT Kanpur for his help in initial work done along with students.

Editors and authors are thankful to Fundação Conrado Wessel for providing the financial support for publishing this article.

\section{FUNDING}

There is no funding for this work.

\section{AUTHOR'S CONTRIBUTION}

Conceptualization: Velamati, KV; Investigation: Murugesan, P.; Arjun B.; Akhil T. K.; Shashank P. and Girish C. C.; Writing - Original Draft: Priyadharshini M.; Arjun B.and Ratna K. V.; Writing - Review and Editing: Ratna K. V. and Srikrishanan A. R.; Resources: Srikrishanan A.R.; Supervision: Ratna K. V. and Srikrishanan A. R.

\section{REFERENCES}

Alkislar M, Choutapalli I, Krothapalli A, Lourenco L (2004) The effect of microjet control on aeroacoustics of supersonic twin jets. Paper presented 42nd AIAA Aerospace Sciences Meeting and Exhibit. AIAA; Reno, Nevada, USA. https://doi.org/10.2514/6.2004-11

André B, Castelain T, Bailly C (2013) Experimental exploration of underexpanded supersonic jets. Shock Waves 24(1):21-32. https:// doi.org/10.1007/s00193-013-0457-4

André B, Castelain T, Bailly C (2014) Investigation of the mixing layer of underexpanded supersonic jets by particle image velocimetry. Int J Heat Fluid Flow 50:188-200. https://doi.org/10.1016/j.ijheatfluidflow.2014.08.004 
Cai J, Tsai HM, Liu F (2010) Numerical simulation of vortical flows in the near field of jets from notched circular nozzles. Comput Fluids 39(3):539-552. https://doi.org/10.1016/j.compfluid.2009.10.006

ChowWL, Chang IS(1972)Mach reflection from overexpanded nozzle flows. AIAAJ 1O(9):1261-1263. https://doi.org/10.2514/3.50368

Chow WL, Chang IS (1975) Mach reflection associated with over-expanded nozzle free jet flows. AIAA J 13(6):762-766. https://doi. org/10.2514/3.60434

Cuppoletti D, Gutmark E, Hafsteinsson H, Eriksson L-E (2014) The role of nozzle contour on supersonic jet thrust and acoustics. AIAA J 52(11):2594-2614. https://doi.org/10.2514/1.J052974

Foss JF, Foss JK, Spalart PR (1989) Numerical and experimental evaluations of the flow past nested chevrons. AlAA J 27(6):675-676. https://doi.org/10.2514/3.10164

Hadjadj A, Kudryavtsev AN, Ivanov MS (2004) Numerical investigation of shock-reflection phenomena in overexpanded supersonic jets. AIAA J 42(3):570-577. https://doi.org/10.2514/1.989

Hu T, Mclaughlin D (1981) Flow and acoustic properties of low Reynolds number supersonic underexpanded jets. Paper presented 7th Aeroacoustics Conference. AIAA; Palo Alto, California, USA. https://doi.org/10.2514/6.1981-1976

Ivanov MS, Markelov GN, Kudryavtsev AN, Gimelshein SF (1998) Numerical analysis of shock wave reflection transition in steady flows. AIAA J 36(11):2079-2086. https://doi.org/10.2514/2.309

Kumar PA, Rathakrishnan E (2013) Truncated triangular tabs for supersonic-jet control. J Propuls Power 29(1):50-65. https://doi. org/10.2514/1.B34642

Li H, Ben-Dor G (1998) Mach reflection wave configuration in two-dimensional supersonic jets of overexpanded nozzles. AlAA J 36(3):488491. https://doi.org/10.2514/2.395

Matsuo S, Setoguchi T, Nagao J, Alam MMA, Kim HD (2011) Experimental study on hysteresis phenomena of shock wave structure in an over-expanded axisymmetric jet. J Mech Sci Technol 25(10):2559-2565. https://doi.org/10.1007/s12206-011-0730-3

Otobe $Y$, Kashimura H, Matsuo S, Setoguchi T, Kim HD (2008) Influence of nozzle geometry on the near-field structure of a highly underexpanded sonic jet. J Fluids Struct 24(2):281-293. https://doi.org/10.1016/j.jfluidstructs.2007.07.003

Punekar, J. N., Avital, E., \& Li, X. (2017). Experimental investigation of nonlinear properties of crackle and screech in supersonic jets. The Journal of the Acoustical Society of America, 141(6), EL567-EL573.

Phalnikar KA, Kumar R, Alvi FS (2007) Experiments on free and impinging supersonic microjets. Experiments in Fluids 44(5):819-830. https://doi.org/10.1007/s00348-007-0438-4

Powell A (2010) On Prandtl's formulas for supersonic jet cell length. Int J Aeroacoust 9(1-2):207-236. https://doi.org/10.1260/1475472X.9.1-2.207

Saddington AJ, Lawson NJ, Knowles K (2002) Numerical predictions and experiments on supersonic jet mixing from castellated nozzles. Paper presented ICAS 2002 Congress. ICAS; United Kingdom.

Schmisseur JD, Gaitonde DV (2011) Numerical simulation of Mach reflection in steady flows. Shock Waves 21(6):499-509. https://doi. org/10.1007/s00193-011-0335-x

Scroggs SD, Settles GS (1996) An experimental study of supersonic microjets. Experiments in Fluids 21(6):40l-409. https://doi. org/10.1007/BFO0189042

Shirie JW, Seubold JG (1967) Length of the supersonic core in high-speed jets. AIAA J 5(11):2062-2064. https://doi. org/10.2514/3.4369

Shimshi E, Ben-Dor G, Levy A (2010) Numeric study of flow separation and shock reflection hysteresis in planar nozzles. International Journal of Aerospace Innovations 2(4):221-233. https:/doi.org/10.1260/1757-2258.2.4.221

Singh A, Chatterjee A (2007) Numerical prediction of supersonic jet screech frequency. Shock Waves 17(4):263-272. https://doi. org/10.1007/s00193-007-0110-1

Tam CKW, Tanna HK (1982) Shock associated noise of supersonic jets from convergent-divergent nozzles. J Sound Vib 81(3):337-358. https://doi.org/10.1016/0022-460X(82)90244-9

Vuillon J, Zeitoun D, Ben-Dor G (1996) Numerical investigation of shock wave reflections in steady flows. AlAA J 34(6):1167-1173. https://doi.org/10.2514/3.13208

Xiao Q, Tsai HM, Papamoschou D (2007) Numerical investigation of supersonic nozzle flow separation. AlAA J 45(3):532-541. https:// doi.org/10.2514/1.20073

Yasunobu T, Matsuoka K, Kashimura H, Matsuo S, Setogushi T (2006) Numerical study for hysteresis phenomena of shock wave reflection in overexpanded axisymmetric supersonic jet. J of Therm Sci 15(3):220-225. https://doi.org/10.1007/s11630-006-0220-6 